\title{
Chapter 25 \\ Simulating NIRS and MRS Measurements During Cerebral Hypoxia-Ischaemia in Piglets Using a Computational Model
}

\author{
T. Hapuarachchi, T. Moroz, A. Bainbridge, S. Faulkner, D. Price, K.D. Broad, \\ D. Thomas, E. Cady, X. Golay, Nicola Robertson, and Ilias Tachtsidis
}

\begin{abstract}
We present a group analysis of the changes in cerebral haemodynamics, and the oxidation state of cytochrome-c-oxidase measured using broadband nearinfrared spectroscopy (NIRS) and intracellular $\mathrm{pH}$ measured by phosphorous $\left({ }^{31} \mathrm{P}\right)$ magnetic resonance spectroscopy (MRS) during and after cerebral hypoxiaischaemia (HI) in 15 piglets. We use a previously published computational model of cerebral metabolism in the piglet [1] to integrate these measurements and simulate HI. We successfully simulate changes in cellular metabolism including shifts in intracellular $\mathrm{pH}$ observed in the piglet brain during HI. In this process, we optimise physiological parameters in the model identified through sensitivity analysis (such as the rate of glucose metabolism and intracellular lactate concentration), to fit simulated and measured data. The model fits the data reasonably and suggests a $20 \%$
\end{abstract}

The original version of this chapter was revised. An erratum to this chapter can be found at DOI 10.1007/978-1-4939-0620-8_49

T. Hapuarachchi $(\triangle)$

CoMPLEX, University College London, London, UK

Department of Medical Physics and Bioengineering, University College London,

Room 3.18, Malet Place Engineering Building, Gower Street, London WC1E 6BT, UK

e-mail: t.hapuarachchi@ucl.ac.uk

T. Moroz

CoMPLEX, University College London, London, UK

A. Bainbridge • D. Price • E. Cady

Medical Physics and Bioengineering, University College London Hospitals, London, UK

S. Faulkner • K.D. Broad • N. Robertson

Institute for Women's Health, University College London, London, UK

D. Thomas • X. Golay

Institute of Neurology, University College London, London, UK

I. Tachtsidis

Department of Medical Physics and Bioengineering, University College London,

Room 3.18, Malet Place Engineering Building, Gower Street, London, WC1E 6BT, UK 
drop in glucose consumption, a $\sim 65 \%$ increase in lactate concentration and $~ 35 \%$ drop in the cerebral metabolic rate of oxygen $\left(\mathrm{CMRO}_{2}\right)$ during $\mathrm{HI}$.

Keywords MRS - Neonatal - Mathematical modelling - Intracellular pH • Parameter optimisation

\section{Introduction}

Piglets are often used in pre-clinical studies to investigate the effect of physiological intra-partum cerebral $\mathrm{HI}$ in mammalian neonates. Using a mathematical and computational model of cerebral metabolism and blood flow, we aim to better understand the complex changes in the brain during these events. The neonatal piglet brain computational model (BrainPiglet) [1] incorporates and simulates NIRS and MRS measurements. These two non-invasive methods are used to monitor brain tissue oxygenation, haemodynamics and metabolism. BrainPiglet was developed from an earlier adult brain model (BrainSignals) [2] —extended to simulate MRS and adapted to the piglet brain. We have recently expanded our model to simulate intracellular $\mathrm{pH}$, considered to be an important biomarker of cerebral pathology [3]. Brain functions are sensitive to changes in $\mathrm{pH}$ as the latter affects protein structure. We further optimise physiological parameters in our model to produce the best simulations that fit the measurements. This is vital when using the model with clinical data as biological parameters can vary with alterations in cerebral pathology. These modifications can convey some information about the physiological changes that occur during HI. In this paper we present averaged measurements of cerebral oxygenation, oxidised cytochrome-c-oxidase (oxCCO) level and intracellular $\mathrm{pH}$ from 15 piglets and compare these with optimised simulations from our BrainPiglet model.

\section{Experimental Methods and Protocol}

In this study, 15 1-day-old piglets were mechanically ventilated and anaesthetised. Inflatable occluders were surgically inserted around the carotid arteries. Normal levels of arterial oxygen and carbon dioxide, blood glucose and heart rate were maintained. Experiments were under UK Home Office Guidelines (Animals [Scientific Procedures] Act, 1986) and approved by the Institute of Neurology, University College London. Changes $(\Delta)$ in concentrations of oxy- and deoxyhaemoglobin $\left(\triangle \mathrm{HbO}_{2}, \Delta \mathrm{HHb}\right)$ and brain oxCCO $(\triangle \mathrm{oxCCO})$ were monitored using broadband NIRS. We used ${ }^{31} \mathrm{P}-\mathrm{MRS}$ to measure changes in concentrations of metabolites such as inorganic phosphate $(\mathrm{Pi})$, phosphocreatine $(\mathrm{PCr})$ and nucleotide triphosphate (NTP; mainly adenosine triphosphate (ATP)). We also estimated intracellular $\mathrm{pH}$ using the ${ }^{31} \mathrm{P}-\mathrm{MRS}$ chemical shifts of $\mathrm{Pi}$ and phosphoethanolamine (PEt) [4]. Comparable with normal clinical practice, we continuously recorded 
systemic variables: arterial blood pressure $\left(\mathrm{P}_{\mathrm{a}}\right)$, arterial oxygen saturation $\left(\mathrm{SaO}_{2}\right)$, breathing rate and heart rate. Firstly baseline ${ }^{31} \mathrm{P}-\mathrm{MRS}$ and NIRS were recorded. Transient HI was then induced (for $\sim 1 \mathrm{~h}$ ) by inflating the occluders and reducing fractional inspired oxygen $\left(\mathrm{FiO}_{2}\right)$ to $12 \%$ from a normal value of $21 \%$. Once $\beta$-NTP had reduced to $\sim 40 \%$ of baseline, $\mathrm{FiO}_{2}$ was gradually returned to normal. This titration was completed over 10-20 min and the carotid occluders were then released. ${ }^{31} \mathrm{P}-\mathrm{MRS}$ and NIRS were acquired simultaneously every $1 \mathrm{~min}$ throughout $\mathrm{HI}$ and for a further $\sim 2 \mathrm{~h}$ to monitor recovery from $\mathrm{HI}[4]$.

\section{Group Analysis of Measurements}

Measurements from experiments in 15 piglets that recovered following $\mathrm{HI}$ are presented in this paper. We examined $\Delta \mathrm{HbO}_{2}, \Delta \mathrm{HHb}$ and $\Delta \mathrm{oxCCO}$ and variations in intracellular $\mathrm{pH}$. We used the difference between $\Delta \mathrm{HbO}_{2}$ and $\Delta \mathrm{HHb}$ as a guide to manually divide the data into five phases: (i) baseline, (ii) start of $\mathrm{HI}$ to start of $\mathrm{FiO}_{2}$ titration, (iii) $\mathrm{FiO}_{2}$ titration period, (iv) release of occluders and recovery, and (v) post recovery from HI. Each phase was subsequently divided into ten sections and data in each section were averaged. The mean of each section across all piglets was calculated. This process was repeated for each measurement variable. The time period of each phase was also averaged across all piglets (Fig. 25.1a).

\section{Model}

BrainPiglet is focused on the physiology of the brain [1], and uses differential equations and algebraic relations to simulate cerebral metabolic activity. This model is complex, incorporating $\sim 100$ parameters and $\sim 25$ variables. It uses $\mathrm{P}_{\mathrm{a}}, \mathrm{SaO}_{2}$, arterial carbon dioxide partial pressure $\left(\mathrm{P}_{\mathrm{a}} \mathrm{CO}_{2}\right)$ and the time of carotid occlusion as inputs to simulate NIRS measurements, such as $\Delta \mathrm{HbO}_{2}, \Delta \mathrm{HHb}$ and $\triangle \mathrm{oxCCO}$, and MRS measurements such as $\mathrm{Pi}, \mathrm{PCr}$, ATP levels and intracellular $\mathrm{pH}$. It also predicts changes in unmeasured quantities such as $\mathrm{CMRO}_{2}, \mathrm{CBF}$ and intracellular lactate concentration. A simple schematic of the model is in Fig. 25.1b.

\section{Results}

Averaged data together with standard deviations are presented in Fig. 25.2. Averaged $\mathrm{SaO}_{2}$ and $\mathrm{Pa}$ were input into the model. $\mathrm{PaCO}_{2}$ was not recorded, however, as the piglets were ventilated, we assumed $\mathrm{PaCO}_{2}$ remains constant at $40 \mathrm{mmHg}$. We used the Morris method [5] to identify the three most influential parameters for $\Delta \mathrm{HbO}_{2}$, 
a
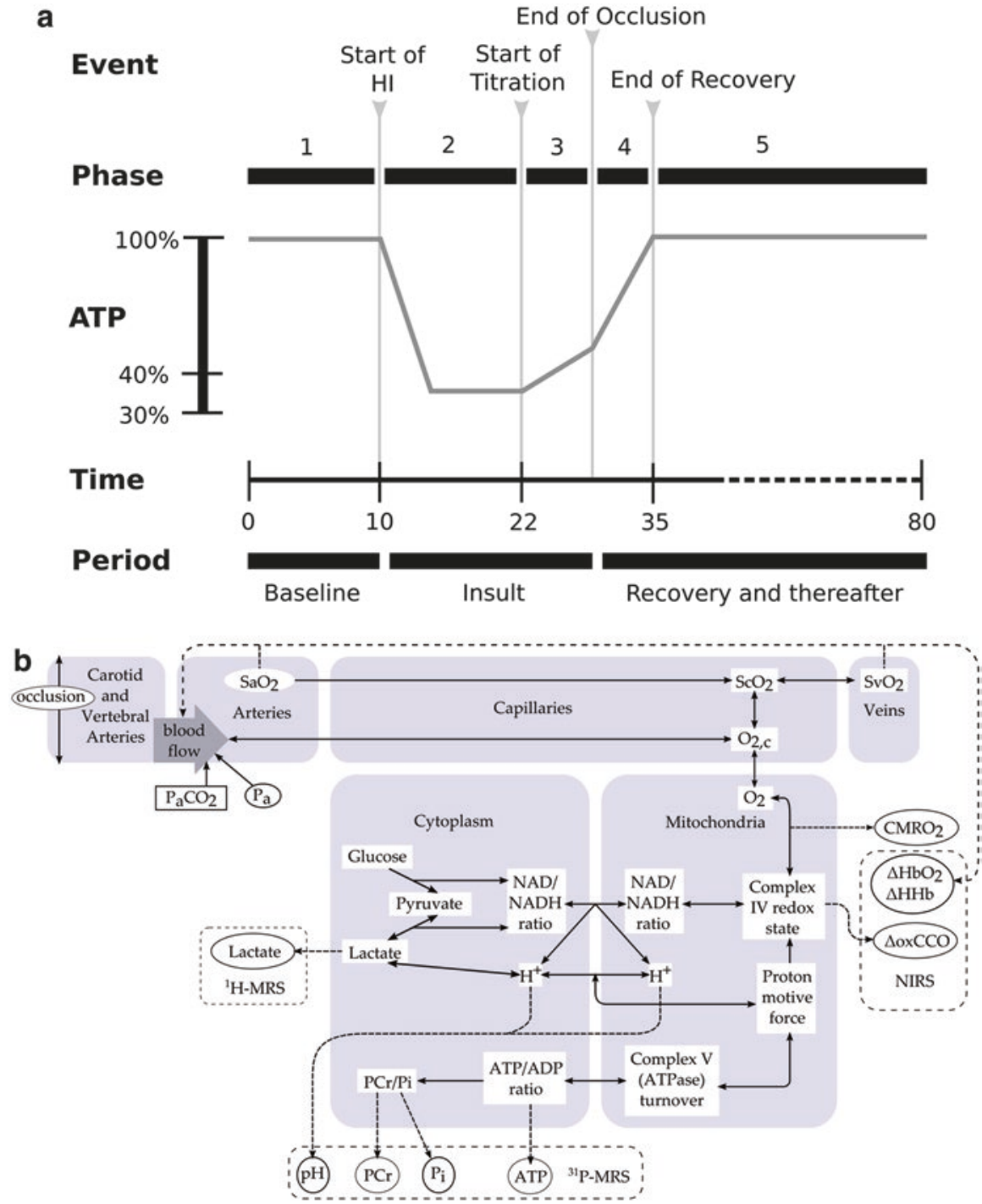

Fig. 25.1 (a) Method for averaging data from 15 piglets - the signals were manually divided into five phases. (b) Schematic of the BrainPiglet model

$\triangle \mathrm{HHb}, \triangle \mathrm{oxCCO}$ and $\mathrm{pH}$. These parameters were then optimised using the PSwarm method [6] to better fit the model to the data. Optimised parameters are presented in Table 25.1 with percentage change compared to their normal values. Also included is the Morris method ranking of influence for the variables we are investigating ( $1=$ most influential). Optimised model simulations are presented in Fig. 25.2. Simulated $\mathrm{CMRO}_{2}$ and cerebral blood flow (CBF) are illustrated in Fig. 25.3. 

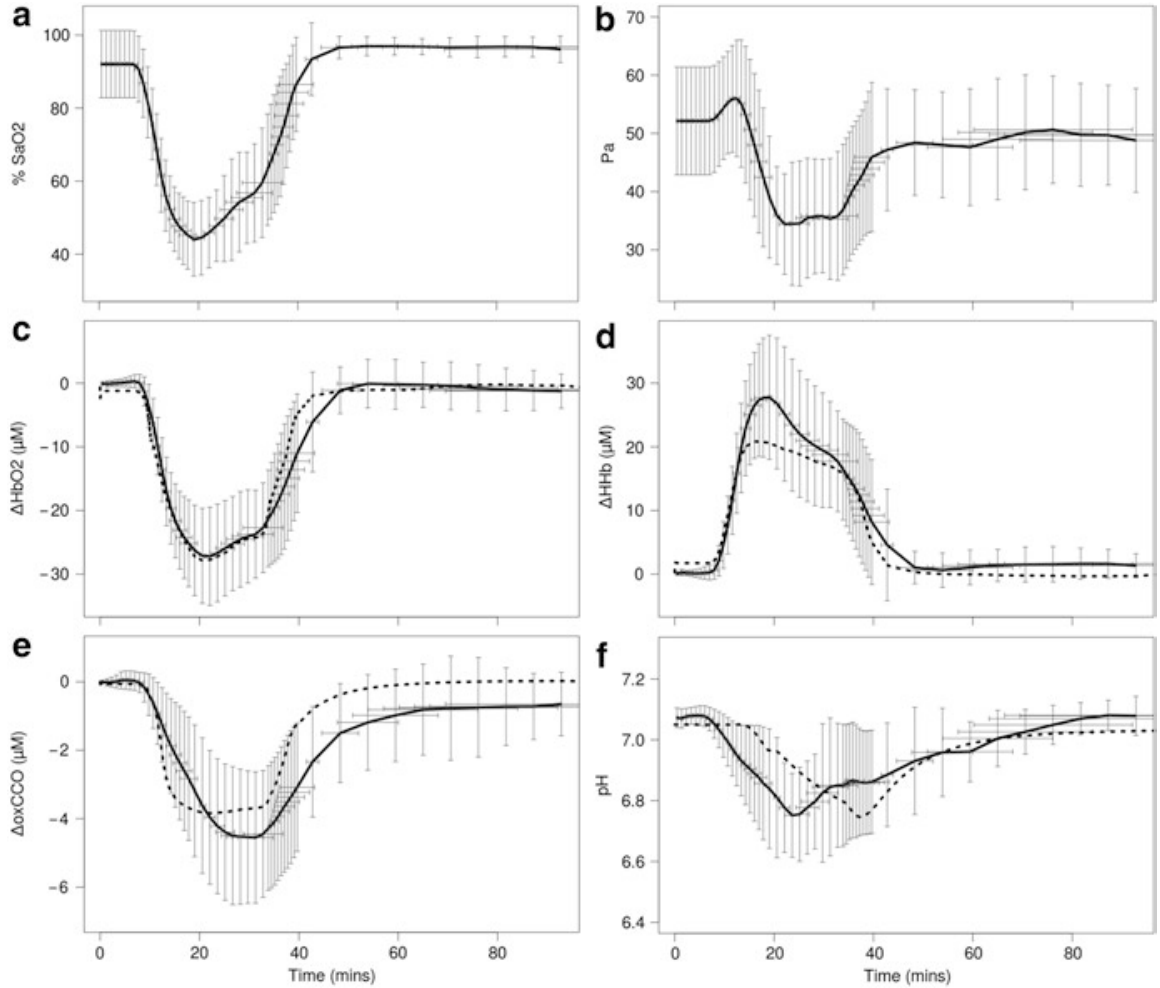

Fig. 25.2 Averaged arterial oxygen saturation $\left(\mathrm{SaO}_{2}, \mathbf{a}\right)$ and blood pressure $\left(\mathrm{P}_{\mathrm{a}}, \mathbf{b}\right)$ measurements are used as inputs to the model; Averaged NIRS and MRS measurements (solid line) compared with modelled results (dotted line): oxyhaemoglobin $\left(\Delta \mathrm{HbO}_{2}, \mathbf{c}\right)$, deoxyhaemoglobin $(\Delta \mathrm{HHb}, \mathbf{d})$, oxidised cytochrome-c-oxidase ( $\triangle \mathrm{oxCCO}, \mathbf{e})$ and intracellular $\mathrm{pH}(\mathbf{f})$. HI starts at $\sim 10 \mathrm{~min}$

Table 25.1 Optimised parameter values and their influence ranked by the Morris method

\begin{tabular}{|c|c|c|c|c|c|c|}
\hline$\underline{\text { Parameter }}$ & $\begin{array}{l}\text { Optimised } \\
\text { value }\end{array}$ & $\begin{array}{l}\text { Percentage } \\
\text { change }(\%)\end{array}$ & $\begin{array}{l}\Delta \mathrm{HbO}_{2} \\
\text { rank }\end{array}$ & $\begin{array}{l}\Delta \mathrm{HHb} \\
\text { rank }\end{array}$ & $\begin{array}{l}\Delta \mathrm{oxCCO} \\
\text { rank }\end{array}$ & $\begin{array}{l}\mathrm{pH} \\
\text { rank }\end{array}$ \\
\hline $\begin{array}{l}\text { Cytochrome-c-oxidase } \\
\text { concentration }\end{array}$ & $0.007 \mathrm{mM}$ & +218 & & & 1 & \\
\hline $\begin{array}{l}\text { Normal cytoplasm lactate } \\
\text { concentration }\end{array}$ & $5.00 \mathrm{mM}$ & +66.7 & & & 3 & 2 \\
\hline $\begin{array}{c}\text { Normal blood total } \\
\text { haemoglobin }\end{array}$ & $6.35 \mathrm{mM}$ & +17.6 & 1 & 1 & 7 & 6 \\
\hline Normal arterial blood pressure & $53.7 \mathrm{mmHg}$ & +7.40 & 7 & 3 & & \\
\hline Normal extra-mitochondrial $\mathrm{pH}$ & 7.05 & +0.007 & & & 6 & 1 \\
\hline Autoregulation constant & 1.00 & No change & 3 & 4 & & \\
\hline $\begin{array}{l}\text { Special radius in the elastic } \\
\text { tension relationship }\end{array}$ & $0.0117 \mathrm{~cm}$ & -7.14 & 2 & 3 & & \\
\hline Normal oxidised fraction of $\mathrm{Cu}_{\mathrm{A}}$ & 0.678 & +1.19 & & & 2 & \\
\hline $\begin{array}{l}\text { Normal blood fraction flowing } \\
\text { through carotid arteries }\end{array}$ & 0.64 & -20.0 & & 2 & 5 & 5 \\
\hline Normal glucose metabolism rate & $0.00352 \mathrm{mM} / \mathrm{s}$ & -20.0 & & & 8 & 3 \\
\hline
\end{tabular}



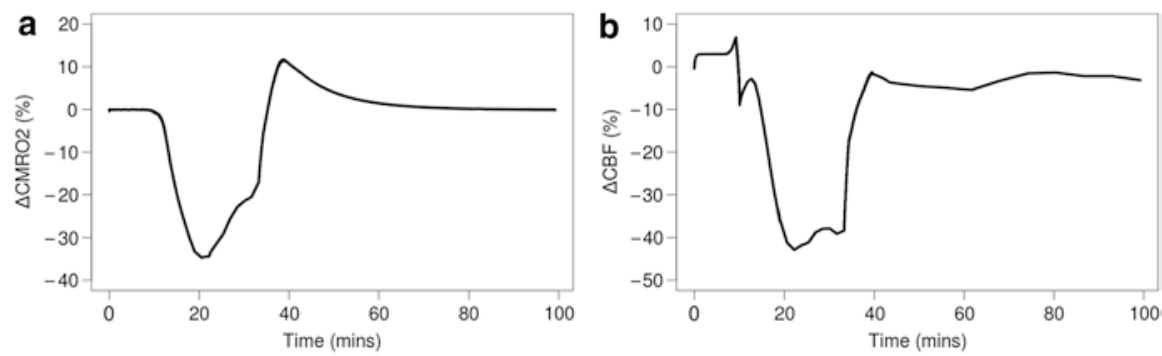

Fig. 25.3 Modelled changes in cerebral metabolic rate of oxygen $\left(\Delta \mathrm{CMRO}_{2}\right.$, a) and cerebral blood flow $(\triangle \mathrm{CBF}, \mathbf{b})$. HI starts at $\sim 10 \mathrm{~min}$

\section{Discussion}

NIRS and MRS measurements offer a valuable insight into the haemodynamic and metabolic events that occur during cerebral HI. Although some large and significant standard deviations (Fig. 25.2) were observed in the measurements, especially during $\mathrm{HI}$, the general trend in these signals is consistent. During HI we observe the expected drop in $\mathrm{SaO}_{2}$ and $\Delta \mathrm{HbO}_{2}$ and rise in $\Delta \mathrm{HHb}$. These concentrations recover very well post $\mathrm{HI}$ and return to baseline levels. $\triangle$ oxCCO decreases during HI, but does not recover so well and fails to return to the baseline after the insult. Just after the start of $\mathrm{HI}$ there is a slight rise in Pa before the major drop during HI. Pa also exhibits significant variation during recovery. While the drop in $\mathrm{pH}$ during $\mathrm{HI}$ is consistent in all the piglets monitored, there is a lot of variation during both recovery and in the time at which recovery commences. In two piglets we observed an increase in the total haemoglobin concentration during HI. This may be due to back circulation of blood through the vertebral arteries during carotid occlusion. However, these piglets exhibited the same variations in the other metabolic quantities we monitored.

We optimised model parameters to get the best fit of model simulations to in-vivo measurements. We decreased the rate of glucose metabolism by $20 \%$ and increased the normal concentration of cytoplasmic lactate by $\sim 65 \%$. This suggests an increase in anaerobic respiration as expected during HI. We significantly increased the concentration of oxCCO. However, the normal model oxCCO concentration $(0.0022 \mathrm{mM})$ is quite low and will be updated in future versions of the model. We increased the normal total haemoglobin concentration in blood and decreased the fraction of blood flowing through carotid arteries. This may well occur during $\mathrm{HI}$ as the carotid arteries are occluded and the vertebral arteries operate at full capacity. The autoregulation constant in the model represents the capacity of the brain to autoregulate, and ranges from 1.0 in a normal brain to 0.0 in the extreme case. The autoregulation capacity of the piglet remained at 1.00 with optimisation, suggesting that these piglets that recovered following $\mathrm{HI}$ are able to autoregulate. Small changes in other parameter values were insignificant. $\Delta \mathrm{HbO}_{2}$ and $\Delta \mathrm{HHb}$ are simulated very well during $\mathrm{HI}$. While $\triangle$ oxCCO compares well with the measurement, a steeper drop in $\triangle \mathrm{oxCCO}$ is modelled. The model also simulates a better recovery to baseline than observed in vivo. Modelled intracellular $\mathrm{pH}$ reaches an acidity during $\mathrm{HI}$ similar to that observed in the 
piglets, but has a more delayed response. This is caused by a buffering mechanism in the model which we are now investigating. Simulated $\mathrm{CMRO}_{2}$ shows $\sim 35 \%$ drop during $\mathrm{HI}$ (Fig. 25.3a). This is contradictory to the long-term drop in $\mathrm{CMRO}_{2}$ observed in piglets by others [7], suggesting that the current dynamics of our model do not account for the persistent reduction. The model has not taken into account cell death during HI, which may contribute to this effect. Simulated CBF also shows $\sim 40 \%$ drop during HI, and a recovery back to baseline (Fig. 25.3b). We must note that parameter optimisation was conducted on measurements over the complete experiment. However, as the physiological state of the brain before and after HI is quite different, we expect, and are currently attempting, to find distinct sets of parameters that suit each stage of the experiment. This will give us a better insight into the physiological changes that occur between these stages. Further, the distribution of the group data was not taken into account in the simulations.

The BrainPiglet model combines our knowledge of cerebral metabolism and experimental data to explore the effect of HI on brain physiology. It enables informed and practical predictions about patient outcome. The model is able to satisfactorily emulate changes in $\mathrm{pH}$ and concentrations of haemoglobin and oxCCO observed during HI. However, while recovery of cerebral haemodynamics and oxygenation is predicted in the model, the metabolic response is not well simulated. This may result from the differing spatial distribution and sensitivity of NIRS and MRS signals-involving cortical and deep white matter, respectively-and the presence of blood in addition to brain tissue in the interrogated tissue volume. Model simulations are also likely to improve with the optimisation techniques outlined above, which will provide more detailed information.

Acknowledgments We would like to thank the Wellcome Trust (088429/Z/09/Z) for financial support of this work. The first author is supported by her doctoral centre CoMPLEX, UCL.

\section{References}

1. Moroz T, Banaji M, Robertson NJ et al (2012) Computational modelling of the piglet brain to simulate near-infrared spectroscopy and magnetic resonance spectroscopy data collected during oxygen deprivation. J R Soc Interface. doi:10.1098/rsif.2011.0766

2. Banaji M, Mallet A, Elwell C et al (2008) A model of brain circulation and metabolism: NIRS signal changes during physiological challenges. PLoS Comput Biol 4(11):e1000212. doi:10.1371/journal.pcbi.1000212

3. Robertson NJ, Cowan FM, Cox IJ et al (2002) Brain alkaline intracellular pH after neonatal encephalopathy. Ann Neurol 52(6):732-742

4. Cady EB, Iwata O, Bainbridge A et al (2008) Phosphorus magnetic resonance spectroscopy $2 \mathrm{~h}$ after perinatal cerebral hypoxia-ischemia prognosticates outcome in the newborn piglet. J Neurochem 107(4):1027-1035

5. Morris MD (1991) Factorial sampling plans for preliminary computational experiments. Technometrics 33(2):161-174

6. Vaz AIF, Vincente LN (2007) A particle swarm pattern search method for bound constrained global optimization. J Global Optim 39:197-219

7. Tichauer KM et al (2005) Near-infrared spectroscopy measurements of cerebral blood flow and oxygen consumption following hypoxia-ischemia in newborn piglets. J Appl Physiol 100:850-857 
Open Access This chapter is licensed under the terms of the Creative Commons Attribution 4.0 International License (http://creativecommons.org/licenses/by/4.0/), which permits use, sharing, adaptation, distribution and reproduction in any medium or format, as long as you give appropriate credit to the original author(s) and the source, provide a link to the Creative Commons license and indicate if changes were made.

The images or other third party material in this chapter are included in the chapter's Creative Commons license, unless indicated otherwise in a credit line to the material. If material is not included in the chapter's Creative Commons license and your intended use is not permitted by statutory regulation or exceeds the permitted use, you will need to obtain permission directly from the copyright holder.

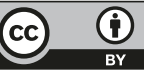

